\title{
Biofertilización y fertilización química en maíz (Zea mays l.) en Villaflores, Chiapas, México
}

\section{Biofertilization and chemical fertilization of corn (Zea mays l.) at Villaflores, Chiapas, México}

\author{
Lucas Martínez Reyes ${ }^{1}$, Carlos Ernesto Aguilar Jiménez², Moisés Graciano Carcaño Montiel³, José Galdámez Galdámez², \\ Antonio Gutiérrez Martíenez², Juan Alonso Morales Cabrera², Franklin B. Martínez Aguilar², Jaime Llaven Martínez², \\ Eraclio Gómez Padilla \\ $凶$ : ejimenez@unach.mx \\ 1 Maestría en Ciencias en Producción Agropecuaria Tropical. Universidad Autónoma de Chiapas. \\ 2 Universidad Autónoma de Chiapas. Facultad de Ciencias Agronómicas. Chiapas. México. \\ 3 Instituto de Ciencias. Centro de Investigaciones en Ciencias Microbiológicas. Benemérita Universidad Autónoma de Puebla.
}

\begin{abstract}
Resumen
El trabajo se realizó con el objetivo de evaluar el efecto de dos biofertilizantes en la producción de maíz, solos y combinados con dos fórmulas de fertilización química. El experimento se realizó bajo un diseño experimental de bloques al azar, con nueve tratamientos y cuatro repeticiones, conformando un total de 36 unidades experimentales. Los biofertilizantes evaluados fueron las especies Azospirillum brasilense y Chromobactherium violaceum, y las fórmulas de fertilización química 80-23-15 y 160-46-30 de N, P y K. El mejor rendimiento de grano de maíz se logró con el tratamiento Azospirillum brasilense + 160-46-30 de N-P-K, con 5.97 t ha-1, en segundo lugar Chromobacterium violaceum $+80-23-15$ de N-P-K con $5.87 \mathrm{t}$ ha-1. El menor rendimiento de $4.30 \mathrm{t}^{\mathrm{ha}^{-}}{ }^{-}$se tuvo con el Testigo absoluto. Los resultados obtenidos muestran que cuando se utiliza biofertilizantes existe un incremento en el rendimiento de maíz por efecto de la aplicación de microorganismos benéficos. El análisis económico mostró que los mayores beneficios netos se tuvieron con los tratamientos Azospirillum brasilense + Chromobacterium violaceum + fertilización química 160-46-30 y Azospirillum brasilense + fertilización quimica 160-46-30. Se concluye que el uso del biofertilizante Azospirillum brasilense representó un incremento en el rendimiento de grano de $27.98 \%$ (1.67 t ha-1) con respecto al testigo absoluto, lográndose un mayor beneficio neto.
\end{abstract}

Palabras clave: bacterias, biofertilizante, fertilización, maíz, rendimiento.

\begin{abstract}
This study conducted was to evaluate the effect of two types of biofertilizers (inoculated beneficial microorganisms) in the production of corn under two formulas of chemical fertilization. It was conducted under an experimental randomized block design with nine treatments and four repetitions, making 36 experimental units. The treatments were Azospirillum brasilense and Chromobactherium violaceum with different fertilization. The highest grain yield of maize was found with treatment Azospirillum brasilense + chemical fertilizer 160-46-30 with $5.97 \mathrm{t}$ ha-1; second Chromobacterium violaceum + chemical fertilizer 80-23-15 with $5.87 \mathrm{t} \mathrm{ha}^{-1}$ and the lowest yield was the absolute control with $4.30 \mathrm{t} \mathrm{ha-}^{-1}$. Results showed that when used biofertilizers there is an increase in corn yield due to the application of beneficial microorganisms, so the hypothesis is not rejected. In the economic analysis the treatment with higher net profits were Azospirillum brasilense + Chromobacterium violaceum + chemical fertilizer 160-46-30 y Azospirillum brasilense + chemical fertilizer 160-46-30 with \$15.576 and \$15.226 respectively. It is concluded that the use of the fertilizer Azospirillum brasilense represented an increase in the grain yield of $27.98 \%$ (1.67 tha-1) with respect to the absolute control and a greater net benefit.
\end{abstract}

Keywords: bacteria, biofertilizer, fertilization, corn, performance. 


\section{Introducción}

En México, el maíz (Zea mays L.) es un cultivo básico para la alimentación humana y animal, su aportación es de $32.8 \%$ del valor de la producción del sector agrícola nacional, ocupando el primer lugar en superficie cultivada (SIAP, 1992); a pesar de su importancia socio-cultural a escala nacional, el proceso de producción fundamentado en los principios de la agricultura campesina, atraviesa desde hace algunas décadas una difícil situación, debido fundamentalmente al incremento del costo de los insumos, principalmente el de los fertilizantes químicos, los cuales representan entre el 40 y $50 \%$ de los costos totales de producción. Esta situación ha traído como consecuencia la necesidad de buscar opciones que puedan ayudar a mejorar la productividad del suelo y que garanticen la producción sostenible del grano básico, una de ellas es el uso de fertilizantes biológicos que permitan mejorar la producción de grano de maíz, así como mejorar las condiciones edáficas, evitando su degradación y contaminación (Carcaño-Montiel et al., 2006).

El uso de biofertilizantes en cultivos básicos ha dado resultados satisfactorios en muchas regiones tropicales, ya que al inocularlos a la semilla favorecen la velocidad de toma de nutrimentos de las plantas por efecto directo en las raíces, así como hacer más eficiente la absorción de los mismos (Aguirre-Medina y Velasco-Zebadúa, 1994). Además, permiten reducir hasta la mitad el uso de fertilizantes sintéticos, fundamentalmente el nitrógeno, fósforo y potasio. $\mathrm{Al}$ reducir la fertilización química disminuye también los costos de producción de maíz, se aprovecha el fósforo y potasio nativo del suelo, y se reduce el efecto acidificante de los fertilizantes nitrogenados amoniacales (Carcaño-Montiel et al., 2006).

Las bacterias del género Azospirillum, producen fitohormonas, como el ácido indolacético y las citoquininas, capaces de acelerar y potenciar el crecimiento de las plantas. Al permanecer vivas durante años y reproducirse en el suelo, contribuyen a su enriquecimiento en nitrógeno y a su regeneración de forma ecológica y gradual, e incluso en terrenos de alta concentración salina (Okon \& Labandera, 1994), a su vez la bacteria Chromobacterium violaceum es una "solubilizadora de fosfatos" que tienen la habilidad de producir sustancias ácidas que liberan el fósforo de los minerales del suelo y así este nutriente puede ser absorbido por las plantas (Rodríguez \& Fraga, 1999).

Por ello, una de las estrategias agroecológicas pertinentes es la utilización de biofertilizantes, que ayudan a la fijación de nitrógeno y a la solubilización de otros nutrimentos como el fósforo y potasio, que pueden reducir los costos de producción, coadyuvar al incremento de los rendimientos y favorecer los factores ecológicos en los agroecosistemas tropicales (Carcaño-Montiel et al., 2006). Tomando en cuenta lo antes expuesto, el presente trabajo estuvo dirigido a evaluar el efecto del Azospirillum brasiliense y Chromobacterium violaceum en la producción de maíz bajo una formula convencional y alternativa de fertilización química.

\section{Materiales y métodos}

\subsection{Ubicación geográfica y tratamientos}

El trabajo se realizó en condiciones de secano durante el ciclo Primavera-Verano 2014, en el predio "La Unión" del municipio de Villaflores, Chiapas, México, ubicado en el kilómetro 85 de la carretera Ocozocoautla-Villaflores, localizado a $\operatorname{los} 16^{\circ} 27^{\prime}$ latitud norte y $93^{\circ} 28^{\prime}$ longitud oeste, el clima que predomina es el cálido subhúmedo $\left(\mathrm{AW}_{1}\right)(\mathrm{W})\left(\mathrm{i}^{\prime}\right) \mathrm{g}$, con una precipitación pluvial media anual de 1.200 $\mathrm{mm}$, distribuidos en los meses de junio a noviembre, con una temperatura promedio de $22{ }^{\circ} \mathrm{C}$ y una altitud de 591 m.s.n.m. (INEGI, 2013).

Las especies de biofertilizante utilizadas fueron Azospirillum brasilense y Chromobacterium violaceum (Carcaño-Montiel et al., 2006). Antes de la inoculación se preparó un adherente con $250 \mathrm{~g}$ de azúcar disuelto en un litro de agua hasta lograr una consistencia pegajosa, los biofertilizantes se agregaron al adherente de acuerdo con cada tratamiento. La inoculación de la semilla de maíz con el biofertilizante se realizó de manera manual, siguiendo las instrucciones del fabricante. La semilla inoculada se dejó secar a la sombra e inmediatamente se sembró en forma manual a espeque. Se realizaron inocula- 
ciones simples y mixtas de acuerdo con los tratamientos bajo estudio.

1. Azospirillum brasilense + fertilización química 80-23-15

2. Chromobacterium violaceum + fertilización química 80-23-15

3. Azospirillum brasilense + C. violaceum + fertilización química 80-23-15

4. Azospirillum brasilense + fertilización química 160-46-30

5. Chromobacterium violaceum + fertilización química 160-46-30

6. Azospirillum brasilense + C. violaceum + fertilización química 160-46-30

7. Fertilización química 80-23-15

8. Fertilización química 160-46-30

9. Testigo absoluto (sin biofertilizante y sin fertilización química)

Se utilizó un diseño de bloques al azar con arreglo combinatorio, en el que se probaron nueve tratamientos en cuatro repeticiones, conformando un total de 36 unidades experimentales, cada unidad experimental tuvo una superficie de $25 \mathrm{~m}^{2}(5 \times 5 \mathrm{~m})$. Para determinar el efecto entre tratamientos se realizó un análisis con el PROC ANOVA SAS para cada variable. Posteriormente, se realizó una comparación de medias de Tukey al 5\% de probabilidad, utilizando el programa computacional Statistical Analysis System versión 8.1. Las gráficas se elaboraron con el Programa Sigma Plot ver 10.0 para Windows.

\subsection{Análisis de componentes agronómicos y de ren- dimiento}

Para evaluar el efecto combinado de los biofertilizantes y fertilizantes químicos se seleccionaron diez plantas de maíz al azar por tratamiento y repetición, donde se determinó el número de días a la emergencia, se midieron altura de planta y de mazorca. En las mazorcas se tomaron los datos de componentes del rendimiento: diámetro y longitud de mazorca, número de hileras, granos por hilera, granos por mazorca, peso de 100 granos y, finalmente se determinó el rendimiento de grano.

\section{Resultados y discusión}

\subsection{Emergencia}

El análisis de varianza no mostró diferencia significativa para la emergencia de plántulas de maíz. Sin embargo, los resultados indican que los tratamientos Chromobacterium violaceum + fertilización química 160-46-30, fertilización química 8023-15 y Azospirillum brasilense + fertilización química 160-46-30, tuvieron los mayores porcentajes de emergencia, mientras que el de menor porcentaje fue el Testigo absoluto (Tabla 1). Pueden observarse incrementos en la emergencia de 52 a $75 \%$ respectivamente, debido al efecto estimulador de los biofertilizantes en la semilla, este incremento obedeció al aporte de hormonas promotoras de crecimiento vegetal. Azospirillum spp. es una bacteria productora de auxinas y giberelinas o bacteria promotora de emergencia, lo cual puede incrementar la emergencia de plántulas (Kloepper et al., 1991).

\subsection{Altura de planta y de mazorca}

Los análisis de varianza mostraron diferencias estadísticas significativas para altura de planta y mazorca. Los resultados indican que el mejor tratamiento para altura de planta fue la fertilización química 160-46-30, seguido de Azospirillum brasilense +80-23-15 y Azospirillum brasilense +160-46-30, mientras que la menor altura se tuvo con el testigo absoluto. La mayor altura de mazorca ocurrió con la fertilización química160+46+30 y con la 80-2315 , la menor altura de mazorca ocurrió con el testigo absoluto (Tabla 1). Con respecto a los biofertilizantes, el mayor crecimiento de plantas se observó en semillas inoculadas con Azospirillum brasilense. Lo cual se debe fundamentalmente a que estos tienen la capacidad de fijar nitrógeno atmosférico que beneficia al crecimiento y desarrollo de las plantas (Bashan et al., 1993).

Los nutrientes son aprovechados directamente por las plantas, o a través de la simbiosis con hongos micorrízicos, cuyos micelios actúan como enlace entre la planta y el suelo (Rodríguez \& Fraga, 1999). Así mismo, la altura de inserción de la mazorca está determinada por el crecimiento genético de la planta e influenciada por factores ambientales entre ellos el agua edáfica, el $\mathrm{pH}$ 
del suelo y la fertilización nitrogenada. También, pueden intervenir algunos microorganismos que son capaces de solubilizar fosfatos (Illmer et al., 1995). Esto origina una estimulación del crecimiento de la planta de maíz y por consecuencia la altura de mazorca debido a la inoculación de bacterias capaces de solubilizar fosfatos orgánicos e inorgánicos (Rodríguez \& Fraga, 1999) aunada a la producción de sustancias reguladoras del crecimiento vegetal (Clark, 2004).

Tabla 1. Efecto de los fertilizantes orgánico e inorgánico en tres variables agronómicas del maíz en Villaflores, Chiapas, México.

\begin{tabular}{|c|c|c|c|}
\hline \multirow[b]{2}{*}{ Tratamientos } & \multicolumn{3}{|c|}{ Variables agronómicas } \\
\hline & $\begin{array}{c}\text { Emergencia } \\
(\%)\end{array}$ & $\begin{array}{l}\text { Altura planta } \\
\text { (m) }\end{array}$ & $\begin{array}{c}\text { Altura de } \\
\text { mazorca } \\
(\mathrm{m})\end{array}$ \\
\hline Chromobacterium v. + fq 160-46-30 & $91.0 \mathrm{~ns}$ & $2.02 \mathrm{bc}$ & $1.00 \mathrm{~cd}$ \\
\hline Fertilización química 80-23-15 & $90.7 \mathrm{~ns}$ & $2.10 \mathrm{abc}$ & $1.45 \mathrm{a}$ \\
\hline Azospirillum $b+$ fq 160-46-30 & $90.7 \mathrm{~ns}$ & $2.07 \mathrm{ab}$ & $1.12 \mathrm{bc}$ \\
\hline Azospirillum $b+$ Chro v. + fq $80-23-15$ & $89.5 \mathrm{~ns}$ & $2.10 \mathrm{abc}$ & $1.22 \mathrm{~b}$ \\
\hline Azospirillum $b+\mathrm{fq}$ 80-23-15 & $89.3 \mathrm{~ns}$ & $2.22 \mathrm{ab}$ & $1.12 \mathrm{bc}$ \\
\hline Azospirillum b + Chro v. + fq 160-46-30 & $89.2 \mathrm{~ns}$ & $2.17 \mathrm{abc}$ & $1.12 \mathrm{bc}$ \\
\hline Chromobacterium v. + fq 80-23-15 & $88.5 \mathrm{~ns}$ & $2.10 \mathrm{abc}$ & $1.20 \mathrm{~b}$ \\
\hline Fertilización química 160-46-30 & $86.2 \mathrm{~ns}$ & $2.32 \mathrm{a}$ & $1.45 \mathrm{a}$ \\
\hline Testigo absoluto & $84.5 \mathrm{~ns}$ & $1.90 \mathrm{c}$ & $0.92 \mathrm{~d}$ \\
\hline
\end{tabular}

Las medias en la columna seguidas con diferentes letras son estadísticamente diferentes (Tukey 0.05). (Emer)=Emergencia, $($ Chro v) $=$ Chromobacterium violaceum, $($ Azospirillum $b)=$ Azospirillum brasilense, $(\mathrm{fq})=$ fertilización química, $(\%)=$ Porcentaje, $(\mathrm{m})=$ metros. ns: no significativo.

\subsection{Componentes de rendimiento}

\section{Peso de mazorca}

Al realizar el análisis de varianza con el peso de mazorcas, no se encontró diferencias estadísticas significativas, sin embargo, hubo mayor cuantificación en los tratamientos Fertilización química 160-46-30, seguido de Azospirillum brasilense + fertilización química 80-23-15, mientras que el peso más bajo se obtuvo con el Testigo absoluto (Tabla 2). El incremento en el peso de mazorca se obtuvo con la menor fórmula de fertilización nitrogenada y semilla inoculada con Azospirillum brasilense, seguido de la inoculación con Chromobacterium violaceum, lo que refleja que existió un mayor efecto de la bacteria Azospirillum y un menor requerimiento de nitrógeno sintético, debido a que la bacteria suministra nitrógeno a la planta y fortalece al crecimiento del cultivo; lo cual ocurre bajo diversos ambientes y condiciones edáficas (Bashan et al., 1993). Además, sintetiza fitohormonas que promueven cambios morfológicos y fisiológicos en la planta, resistencia a estrés y micro-biocontrol, variables no medidas en este estudio, que generan un mejor aprovechamiento de agua, nutrientes y un incremento en el rendimiento de grano (Tortora et al., 2011). 
Tabla 2. Efecto de biofertilizantes y fertilizantes inorgánicos en el peso de mazorcas de maíz

\begin{tabular}{|c|c|}
\hline Tratamientos & Peso de 10 mazorcas $(\mathrm{kg})$ \\
\hline Fertilización química 160-46-30 & $1.79 \mathrm{~ns}$ \\
\hline Azospirillum brasilense + fq 80-23-15 & $1.69 \mathrm{~ns}$ \\
\hline Chromobacterium $v+$ fq 80-23-15 & $1.66 \mathrm{~ns}$ \\
\hline Azospirillum $b+$ Chromobacterium $v+\mathrm{fq} 80-23-15$ & $1.66 \mathrm{~ns}$ \\
\hline Fertilización química 80-23-15 & $1.64 \mathrm{~ns}$ \\
\hline Azospirillum $b+$ Chromobacterium $v+$ fq 160-46-30 & $1.64 \mathrm{~ns}$ \\
\hline Azospirillum brasilense + fq160-46-30 & $1.62 \mathrm{~ns}$ \\
\hline Chromobacterium v + fertilización química 160-46-30 & $1.54 \mathrm{~ns}$ \\
\hline Testigo absoluto & $1.31 \mathrm{~ns}$ \\
\hline
\end{tabular}

$\mathrm{ns}=$ no significativo

La fertilización química, por ser de reacción inmediata, superó a los tratamientos con semilla inoculada con Azospirillum, el efecto positivo de los biofertilizantes se atribuye principalmente al mejoramiento en el desarrollo de la raíz y al incremento subsecuente en la tasa de asimilación de agua (Dobbelaere et al., 2001).

\section{Diámetro y longitud de mazorca}

Con el análisis de varianza no se encontró diferencias estadísticas significativa

s para el diámetro de mazorca. Los resultados señalan que los tratamientos $A$. brasilense $+C$. violaceum + fertilización química 80-23-15, fertilización química 160-46-30 y Chromobacterium violaceum + fertilización química 160-46-30, cuantificaron las mejores medias, mientras que el de menor diámetro se cuantificó en el Testigo absoluto (Figura 1). El efecto de Chromobacterium violaceum fue el de potencializar el fósforo que se encuentra en la solución del suelo; mientras que el mayor efecto en el proceso fotosintético es atribuible al nitrógeno aportado por A. brasilense.

Las diferencias en los diámetros promedio de mazorca por efecto de Azospirillum también pueden atribuirse a las giberelinas producidas y a su modo de acción en el aumento del tamaño; en adición al efecto del potencial de agua, es decir, concentración de $\mathrm{O}_{2}$ y producción de giberelinas $\mathrm{A} 3$, las cuales producen células con capacidad de utilizar altas cantidades de agua, crear resistencia a la sequía y contribuir a una adecuada formación del fruto (Piccoli et al., 1997).

Los resultados obtenidos para la variable diámetro de mazorca muestran la efectividad de la bacteria Chromobacterium violaceum como solubilizadora de fosfatos insolubles, ya que éstas tienen la función de poner a disponibilidad de la planta el fósforo que está en el suelo (Tortora et al., 2011), si bien en este estudio no se registra significancia estadística para esa variable. Estas bacterias permiten un mejor aprovechamiento de este nutrimento, sobre todo cuando se combina con otros elementos como hierro, aluminio, calcio y magnesio. Cuando se incorporan al suelo bacterias solubilizadoras de fosfato, tienen la capacidad de producir ácidos orgánicos que liberan a este elemento de los demás, para ser así asimilado por las raíces en forma de ion ortofosfato: $\mathrm{HPO}_{4}^{-2} \mathrm{o}_{2} \mathrm{PO}_{4}^{-}$. Estas bacterias producen enzimas llamadas fosfatasas, que liberan las formas orgánicas de fosfato en el suelo y las incorporan a la planta. Además, son reguladoras del crecimiento porque producen hormonas (Carcaño-Montiel et al., 2006).

Al realizar el análisis de varianza para longitud de mazorca, no se encontró diferencias estadísticas significativas; sin embargo, los tratamientos 
que respondieron favorablemente fueron Chromobacterium violaceum + fertilización química 80 23-15, seguido de fertilización química 160-46-30, mientras que la menor longitud de mazorca se obtuvo con el testigo absoluto (Figura 1). Esto indica que una pequeña deficiencia de fósforo en la solución del suelo implica retrasos en el crecimiento de la planta. Estos resultados también muestran una posibilidad de reducción de las dosis de nitrógeno y fósforo de hasta $50 \%$, sin disminuir la longitud de la mazorca, con lo cual se demuestra las bondades de la utilización de los biofertilizantes a base de bacterias solubilizadoras de fosfatos (Chromobacterium violaceum) en la producción de maíz.
El mecanismo que la bacteria Chromobacterium violaceum utiliza es mediante la solubilización de fosfatos y producción de hormonas, en el caso de Azospirillum brasilense es la fijación de nitrógeno, lo que incrementa la asimilación de agua y minerales, mejorando el desarrollo radicular (Caballero-Mellado, 2014), aumentando la actividad enzimática de la planta o auxiliando a otros microorganismos benéficos para que actúen de mejor manera sobre las plantas (Bashan et al., 1993). Azospirillum brasilense confiere tolerancia al estrés osmótico a las plantas de maíz inoculadas, lo cual origina un aumento en la biomasa de las plantas (Vital \& Mendoza, 2014).

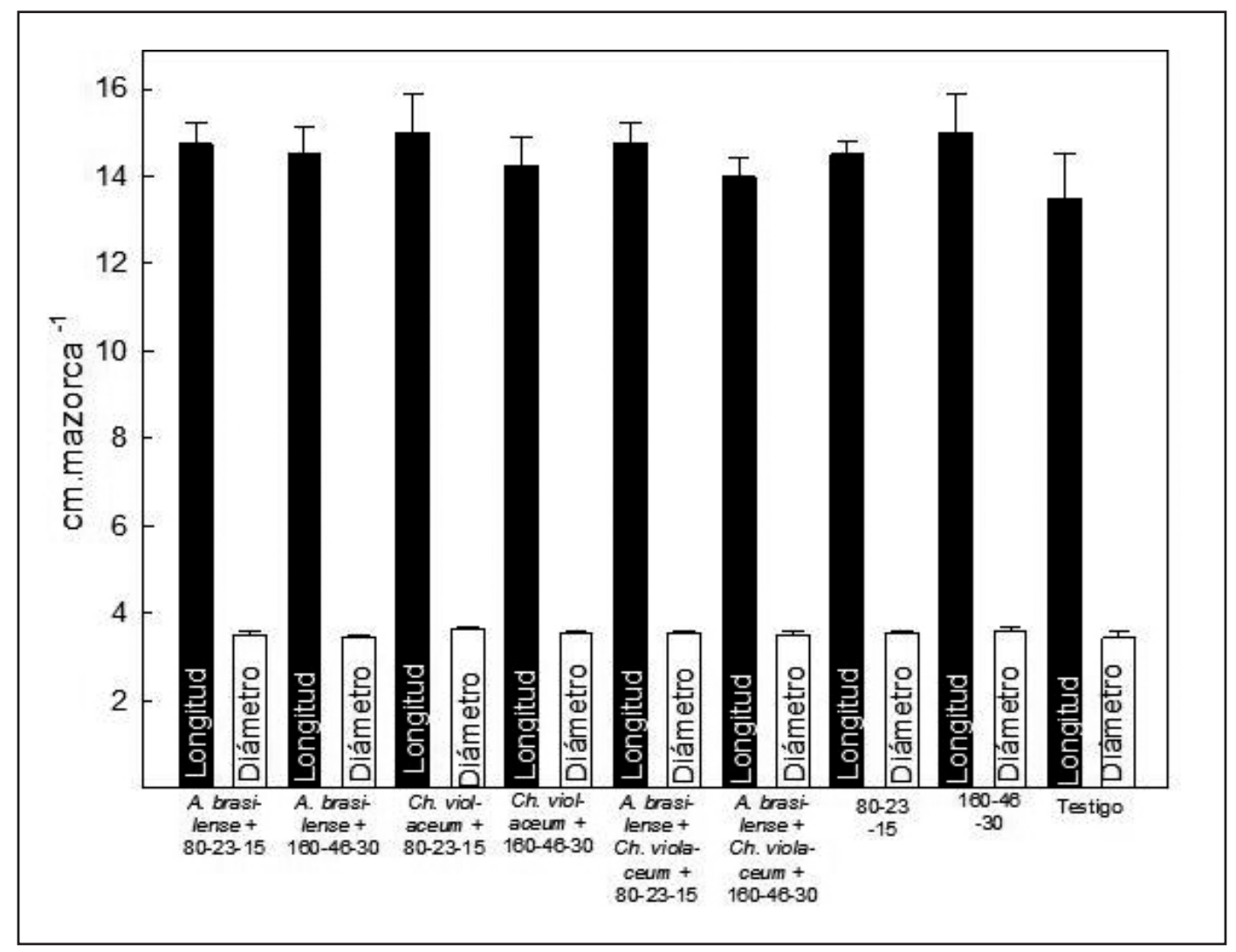

Figura 1. Efecto de los biofertilizantes en el diámetro y longitud de mazorcas de maíz. (Azos b) =azospirillum brasilense, $($ Chro v) $=$ Chromobacterium violaceum, $($ Test $)=$ Testigo

\section{Número de hileras y granos por hilera}

Al realizar el análisis de varianza para el número de hileras por mazorca, no se encontró diferencias estadísticas significativas. Los resultados obtenidos señalan que los tratamientos Azospirillum brasilense + Chromobacterium violaceum + fertilización química 160-46-30, Azospirillum brasilense + fertilización química 80-23-15. (Figura 2) tuvieron incrementos numéricos, mientras que el tratamiento Chromobacterium violaceum + fertilización química 160-46-30, fue el de menor número de hileras. Aunque el número de hileras es un carácter genético, los resultados muestran que Azospirillun tuvo un efecto sinérgico con la mayor dosis de fertilización nitrogenada. Evidencia previa reporta resultados similares a los aquí reportados al combinar cepas de Azospirillum brasilense y Chromobacterium viola- 
ceum para la producción de maíz (Carcaño-Montiel et al., 2006).

Al igual que para el número de hileras, no se encontró diferencia estadística significativa para el número de granos por hilera. Los resultados obtenidos, señalan que los tratamientos Chromobacterium violaceum + fertilización química 160-46-30 y Azospirillum brasilense + fertilización química 160-4630 , influyeron favorablemente en esta variable, con un incremento del $29.5 \%$ para ambos tratamientos. seguido de Azospirillum brasilense + Fertilización química 80-23-15, mientras que el Testigo absoluto fue el de menor granos por hileras (Figura 2). Al aplicar biofertilizantes, el incremento en los componentes de rendimiento de maíz se debe al suministro de nitrógeno que se aporta a través de los distintos biofertilizantes aplicados, lo que ayuda a la incorporación de nitrógeno a la planta (Dobbelaere et al., 2001). Caracaño (s/f) señala que la eficiencia del fósforo aplicado como fertilizante químico es menor a $20 \%$, sobre todo en suelos con $\mathrm{pH}$ ácidos o alcalinos, en los que $80 \%$ de fósforo restante se fija al suelo en poco tiempo y no puede ser utilizado por el cultivo, en estas condiciones, la bacteria Chromobacterium violaceum tiene la capacidad de solubilizar fosfatos y producir sustancias reguladoras del crecimiento vegetal.

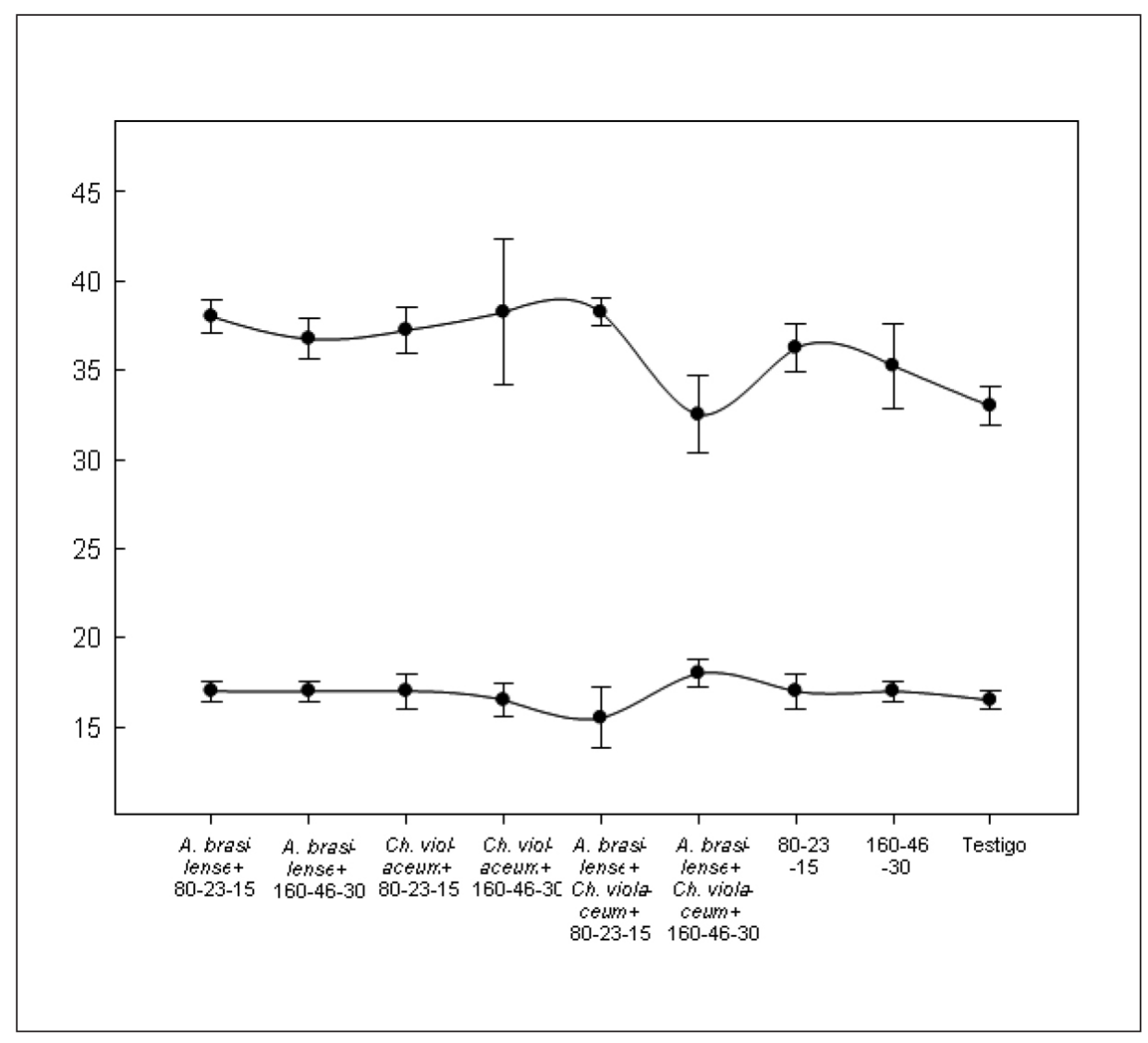

Figura 2. Efecto de biofertilizantes sobre el número de hileras y granos por hileras en mazorca de maíz. La línea vertical indica \pm el error estándar de cuatro repeticiones. (Azos b) $=$ Azospirillum brasilense, $($ Chro $v)=$ Crhomobacterium violaceum, $($ Test $)=$ Testigo

Por su parte, las bacterias del género Azospirillum spp., mejoran el crecimiento vegetal, dada la producción y liberación de fitohormonas (Bashan et al., 1993). Las plantas presentan cambios morfológicos en las raíces, así como también una mejor absorción de minerales después de inocularse con Azospi- rillum spp; estos cambios se atribuyen a la liberación del ácido indolacetico (Steenhoudt and Vanderleyden, 2000). Por lo tanto, el aumento de la superficie de absorción de nutrientes mejora algunas características morfofisiológicas de las plantas, tales como número de hileras y número de granos por hilera. 


\section{Granos por mazorca y peso de 100 granos}

Al igual que las anteriores variables, no se encontraron diferencias estadísticas significativas para granos por mazorca y peso de 100 granos. Sin embargo, para granos por mazorca, los mejores resultados se obtuvieron con los tratamientos Azospirillum brasilense + fertilización química 80-23-15 y Azospirillum brasilense + Chromobacterium violaceum + fertilización química 80-23-15, mientras que para el Testigo absoluto los resultados fueron inferiores (Tabla 3). Lo anterior sugiere que azospirilum reduce el requerimiento de nitrógeno sintético y Chromobacterium fortalece con fósforo para mejorar ambos componentes del rendimiento de maíz. También se observó que la eficiencia del nitrógeno está estrechamente relacionada con las aplicaciones de fertilizantes fosfatados, con incrementos de hasta el $18 \%$ en el número de granos por mazorca. Al respecto, Irízar et al. (2003) encontraron que la combinación de un biofertilizante regulador del crecimiento vegetal más la fertilización de fosforo y potasio al momento de la siembra incrementan el número de granos por mazorca. El biofertilizante permite a la planta incrementar la exploración de la raíz con un aumento en la absorción y transporte de nutrientes como fósforo, nitrógeno, cobre, zinc y agua del suelo, proporcio- nándole mayores ventajas para su desarrollo y productividad (Glick et al., 1999).

Con el peso de 100 granos se muestra que hubo sinergia entre las bacterias Azospirillum y Chromobacterium inoculadas y los fertilizantes químicos, requiriendo menor cantidad de este último y con respuesta favorable, mientras que el Testigo absoluto fue el de menor peso (Tabla 3 ).

Los mayores pesos de 100 granos encontrados se pueden atribuir a la acción conjunta de cepas de Azospirillum con fertilizante químico por la capacidad de ambos de suministrar carbohidratos al momento del llenado de grano y por el aporte de fósforo y potasio debido al fertilizante químico (Dobbelaere et al., 2001).

Cabe señalar que Azospirillum brasilense es una rizobacteria fijadora de nitrógeno del aire, que promueve el crecimiento cuando es inoculada, especialmente en gramíneas (Aguirre \& Velazco, 1994). Los resultados obtenidos en otros estudios muestran que la respuesta a la inoculación varía en función de la variedad del cultivo, grado de fertilidad y tipo de suelo, clima y disponibilidad de agua en el suelo, observándose mejores resultados en suelos con tendencia arenosa y niveles intermedios de fertilización (Bashan et al., 1996; Caballero-Mellado, 2014)

Tabla 3. Efecto de biofertilizantes y fertilizantes químicos

\begin{tabular}{lcc}
\hline \multicolumn{1}{c}{ Tratamiento } & Granos por mazorca & Peso de 100 granos (g) \\
\hline Azospirillum $b .+$ fertilización q 80-23-15 & $644 \mathrm{~ns}$ & $26.2 \mathrm{~ns}$ \\
Azospirillum $b .+$ Chromobacterium $v+$ fq $80-23-15$ & $630 \mathrm{~ns}$ & $26.0 \mathrm{~ns}$ \\
Chromobacterium v. + fertilización q 80-23-15 & $624 \mathrm{~ns}$ & $26.0 \mathrm{~ns}$ \\
Azospirillum brasilense + fertilización q 160-46-30 & $620 \mathrm{~ns}$ & $25.0 \mathrm{~ns}$ \\
Fertilización química 160-46-30 & $619 \mathrm{~ns}$ & $25.2 \mathrm{~ns}$ \\
Fertilización química 80-23-15 & $598 \mathrm{~ns}$ & $26.2 \mathrm{~ns}$ \\
Chromobacterium v. + fertilización q 160-46-30 & $591 \mathrm{~ns}$ & $25.2 \mathrm{~ns}$ \\
Azospirillum $b .+$ Chromo $v .+$ fq 160-46-30 & $584 \mathrm{~ns}$ & $26.0 \mathrm{~ns}$ \\
Testigo absoluto & $486 \mathrm{~ns}$ & $25.2 \mathrm{~ns}$ \\
\hline
\end{tabular}

ns: no significativo 


\section{Rendimiento de grano}

No se encontró diferencias estadísticas significativas para el rendimiento de grano, al igual que los componentes de esta variable: número de hileras, granos por hilera, granos por mazorca y peso de grano. Los resultados señalan un incremento con los tratamientos Azospirillum brasilense + fertilización química 160-46-30, Chromobacterium violaceum + fertilización química 80-23-15, con estos se obtuvo $5.97 \mathrm{t} \mathrm{ha}^{-1}$ y 5.87 tha $^{-1}$ de maíz respectivamente, mientras que la menor producción unitaria se tuvo con el Testigo absoluto (Tabla 4).

Cabe resaltar que aunque no se registraron diferencias significativas, el tratamiento de Azospirillum brasilense + fertilización química 160-46-30 produjo un incremento del $38 \%$ de rendimiento de grano de maíz por sobre el testigo absoluto, como resultado de los componentes número de hileras y granos por hilera, los cuales a su vez contribuyeron al incremento en el número de granos por mazorca al utilizar la combinación de Azospirillum brasilense+ Chromobacterium violaceum + fertilización química 80-23-15. Estos resultados se repiten con la aplicación de Chromobacterium violaceum + fertilización química 80-23-15, obteniéndose un $36.5 \%$ de incremento en el rendimiento final. Los resultados obtenidos muestran que la utilización de Azospirillum brasilense producen un incremento en el rendimiento de maíz por efecto de la aplicación de microorganismos benéficos, efecto que puede ser atribuible a la estimulación del crecimiento de la raíz, una mayor superficie de absorción de nutrientes, un mayor crecimiento de la parte aérea y al incremento de N-P-K en las plantas inoculadas de acuerdo a lo propuesto por Okan \& Labandera (1994) y Aguilera et al. (2008); el uso de microorganismos benéficos permite incrementar el rendimiento de grano del 5 a $30 \%$ y en promedio para México 26\% bajo diferentes tipos de suelo, clima y variedad de cultivo (Caballero Mellado, 2014). Los resultados obtenidos en este estudio son semejantes a lo que reporta este último autor. Sin embargo, éstos difieren de los reportados por Carcaño-Montiel et al. (2003) y García et al. (2005), quienes encontraron incrementos del 8\% al usar Azospirillum brasilense en lugar del testigo fertilizado químicamente. Irízar et al. (2003) registran un 60\% de incremento en maíz, utilizando $A$. brasilense, sobre la fertilización química. Estos datos indican que la bacteria tiene un efecto estimulador variado en el rendimiento debido a las diferentes condiciones edafoclimáticas y a la producción de citocininas, giberelinas y auxinas, de esta última, especialmente la del ácido indol acético el cual puede modificar el balance de fitohormonas permitiendo la germinación de la semilla de maíz y el incremento en la longitud y volumen de raíces, lo que mejora la absorción de nutrientes y finalmente la transferencia de una gran cantidad de minerales (Bashan, et al, 1993; Tortora et al., 2011).

Tabla 4. Efecto de biofertilizantes y fertilización química en el rendimiento de grano de maíz.

\begin{tabular}{lc}
\hline \multicolumn{1}{c}{ Tratamiento } & Rendimiento de grano (tha-1) \\
\hline Azospirillum brasilense + fertilización química 160-46-30 & $5.97 \mathrm{~ns}$ \\
Chromobacterium $v+$ fertilización química $80-23-15$ & $5.87 \mathrm{~ns}$ \\
Azospirillum $b+$ Chromobacterium v + fq 160-46-30 & $5.67 \mathrm{~ns}$ \\
Fertilización química 160-46-30 & $5.62 \mathrm{~ns}$ \\
Fertilización química 80-23-15 & $5.57 \mathrm{~ns}$ \\
Azospirillum $b+$ fertilización química 80-23-15 & $5.55 \mathrm{~ns}$ \\
Azospirillum $b+$ Chromobacterium violaceum + fq 80-23-15 & $5.52 \mathrm{~ns}$ \\
Chromobacterium violaceum + fertilización química 160-46-30 & $4.37 \mathrm{~ns}$ \\
Testigo absoluto & $4.30 \mathrm{~ns}$ \\
\hline
\end{tabular}

ns: no significativo 


\subsection{Análisis económico}

Se realizó el análisis económico, considerando todos los insumos empleados para la siembra de maíz bajo los tratamientos de biofertilizantes y fertilización química, considerando los precios de acuerdo con el año 2014. Se determinaron los costos variables y se les relacionó con el beneficio neto y la tasa marginal de retorno (CIMMYT, 1988).
Los mayores costos de producción se generaron con los tratamientos Azospirillum brasilense + Chromobacterium violaceum + fertilización química 160-46-30 y Azospirillum brasilense + fertilización química 160-46-30; mientras que los menores se observaron para los tratamientos Chromobacterium violaceum + fertilización química 80-23-15 y Azospirillum brasilense + fertilización química 8023-15 (Tabla 5), lo que muestra que la fertilización química es la que encarece la producción de maíz.

Cuadro 5. Costos de producción y beneficios netos en el cultivo de maíz.

\begin{tabular}{|c|c|c|}
\hline Tratamientos & $\begin{array}{c}\text { Costos de producción } \\
(\$)\end{array}$ & $\begin{array}{c}\text { Beneficios netos } \\
\text { (\$) }\end{array}$ \\
\hline Azos $b+$ Chro $v+$ fertilización q 160-46-30 & 5,894 & 15,576 \\
\hline Azospirillum $b .+$ fertilización q 160-46-30 & 5,774 & 15,576 \\
\hline Chromobacterium v. + fq 80-23-15 & 5,319 & 15,226 \\
\hline Azospirillum $b .+$ fertilización q 80-23-15 & 5,319 & 14,106 \\
\hline
\end{tabular}

\$: Pesos Mexicanos

Los mayores beneficios netos se obtuvieron con los tratamientos Azospirillum brasilense + Chromobacterium violaceum + fertilización química 160-46-30 y Azospirillum brasilense + fertilización química 160-46-30. La diferencia en los costos de producción se atribuye a Chromobacterium violaceum con $\$ 120.00$. Estos resultados sugieren que se obtienen mayores beneficios netos al aplicar un biofertilizante adicional a la fertilización química. A pesar de existir una variación en la influencia de los tratamientos, al realizar la conversión costo-beneficio, la aplicación de la bacteria Azospirillum brasilense conduce a un mayor beneficio económico. Esto indica que la aplicación del Azospirillum brasilense, puede ser una opción en los agroecosistemas de secano para mejorar y recuperar la fertilidad de los suelos; así como para disminuir la dosis de nitrógeno inorgánico requerido para un mayor rendimiento de grano (Bashan et al., 1993). Adicionalmente, la sustitución parcial de los fertilizantes inorgánicos por biofertilizantes podría disminuir significativamente la contaminación ambiental, degradación del suelo y contaminación del agua del subsuelo (Caballero-Mellado, 2014)

\section{Conclusiones}

Este estudio ha analizado los resultados aquí presentados, muestra que los mejores rendimientos de grano de maíz se obtuvieron con los tratamientos Azospirillum brasilense + fertilización química 16046-30 con $5.97 \mathrm{t} \mathrm{ha}^{-1} \mathrm{y}$ con el tratamiento Chromobacterium violaceum + fertilización química 80-2315 , con $5.87 \mathrm{t} \mathrm{ha}^{-1}$. El rendimiento más bajo se tuvo con el testigo absoluto. Los mayores beneficios netos se registraron al usar los tratamientos Azospirillum brasilense + Chromobacterium violaceum + fertilización química 160-46-30 y Azospirillum brasilense + fertilización química 160-46-30. Se concluye que el uso del biofertilizante Azospirillum brasilense representó un incremento de $27.98 \%\left(1.67 \mathrm{tha}^{-1}\right)$ en el rendimiento de grano y con un mayor beneficio neto con respecto al testigo absoluto. 


\section{Referencias}

Aguilera, G., L. I. V. Olalde P., M. Rubí A., \& R. Contreras A. (2008). Micorrizas arbusculares. Ciencia ergo sum, 14(3), 300-306.

Aguirre-Medina, J. F., \& Velasco-Zebadúa, E. (1994. Componentes morfológicos y fisiológicos del rendimiento en Leucaena leucocephala Lam. (De Wit) al inocularse con micorriza VA y/o Rhizobium loti. Agricultura técnica en México, 20(1), 43-54.

Bashan Y., Holguín, G., \& Ferrera-Cerrato, R (1996). Interacciones entre plantas y microorganismos benéficos Azospirillum. Terra, 14, 159-183.

Bashan, Y. Holguín, G., Puente, E., Carrillo, M. A., Alcaraz-Méndez, L., López-Cortes, A., \& Ochoa J., L. (1993). Critical evaluation of plant inoculation whith benefical bacteria from the genus Azospirillum. In: Ferrera-Cerrato, R. y Quintero L., R. (eds.). Agroecología, sostenibilidad y educación (pp. 115-123). Colegio de Posgraduados. Centro de Edafología. Montecillos, Estado de México.

Caballero-Mellado J. (2014). El género Azospirillum. Programa de Ecología Molecular y Microbiana, Centro de Investigación sobre Fijación de Nitrógeno. México: UNAM.

Carcaño M. s/f. Transferencia cientifica-tecnológica a favor del agro y el medio ambiente. Disponible en: http://www.educacionyculturaaz.com/ articulos-az/transferencia-cientifica-tecnologica-a-favor-del-agro-y-el-medio-ambiente. Revista de Educación y cultura.

Carcaño-Montiel, M.G., Mascarúa-Esparza, M.A. \& López Reyes, L. (2003). Producción y comercialización de inoculantes bacterianos en México. García Calderón, N.E., et al., Suelos: un enfoque holístico para su manejo y conservación. España: BUAP, UNAM, CSIC-ESPAÑA.

Carcaño-Montiel, M.G., Ferrera-Cerrato, R., Pérez-Moreno, J., Molina-Galán, J.D., \& Bashan. Y. (2006). Actividad nitrogenasa, producción de fitohormonas, sideróforos y antibiosis en cepas de Azospirillum y Klebsiella aisladas de maíz y teocintle. Terra Latinoamericana, 24, 493-502.

Centro Internacional de Mejoramiento de Maíz y Trigo (CIMMYT). (1988). La formulación de recomendaciones a partir de datos agronómicos: Un manual metodológico de evaluación económica (pp. 10-77). Edición completamente revisada. México D.F., México: CIMMYT.

Clark, B. L. (2004). Characterization of a catechol-tipe siderophore and the detection of a posible outer membrane receptor protein from Rhizobium leguminosarum strain IARI 312. Electronic Theses and Dissertations. Paper 922. https://dc.etsu.edu/etd/922

Dobbelaere, S., Croonenborghs, A., Thys, A., Ptacek, D., Vanderleyden, J.; Dutto, P.; Labandera-González, C.; Caballero-Mellado, J.; Aguirre, J. F.; Kapulnik, Y.; Brener, S.; Burdman, S.; Kadouri, D.; Sang, S., \& Okón, J. (2001). Responses of agronomically important crops to inoculation with Azospirillum. Aust. Functional Plant Biology, 28(9), 871-879.

García, O.J.G, Moreno M., V.R., Rodríguez L., C.I., Mendoza H., A., \& Mayek P., N. (2005). Efecto de cepas de $A$. brasilense en el crecimiento y rendimiento de grano de maíz. Revista Fitotecnia Mexicana, 30(3), 305-310.

Glick, B.R, Patten, C.L., Holguin, G., \& Penrose, D. M. (1999). Biochemical and Genetic Mechanism Used by Plant Growth Promoting Bacteria. London: Imperial College Press.

Illmer, P., Barbato, A., \& Schinner, F. (1995). Solubilization of hardly- soluble $\mathrm{AlPO}_{4}$ with $\mathrm{P}$-Solubilizing microorganisms. Soil Biology and Biochemistry, 27, 265-270.

Instituto Nacional de Estadística y Geografía (INEGI). (2013). Anuario estadístico y geográfico de los Estados Unidos Mexicanos. Disponible en: http://www.inegi.org.mx/.

Irízar, G.M., Vargas, P., Garza, D., Tut, C., Rojas, M., Trujillo, A., García, R., Aguirre, M., Martínez, J., Alvarado, S., Grageda, O., Valero, J., \& Aguirre, J. (2003). Respuesta de cultivos agrícolas a los biofertilizantes en la región central de México. Agricultura técnica en México, 29, 213-225.

Kloepper J.W., Zablotowick, R.M., Tipping, E.M., \& Lifshitz, R. (1991). Plant growth promotion mediated by bacterial rhizosphere colonizers. Keister, D.L., \& Cregan, P.B. (eds), The Rhizosphere and Plant Growth (pp. 315-326). Dordrecht: Kluwer Academic Publishers. 
Okon, J. \& Vanderleyden. (2002). Effect of inoculation with wild type Azospirillum brasilense and A. irakense strains on development and nitrogen uptake of spring wheat and grain maize. Biology and Fertility of Soils, 36(4), 284-297.

Okon, Y. \& Labandera, C. (1994). Agronomic applications of Azospirillum evaluation of 20 years worldwide field inoculation. Soil Biology and Biochemistry, 26(12), 1591-160.

Piccoli, P., Lucangeli, C., Achneider, G., \& Bottini, R. (1997). Hydrolysis of $\left[17,17-{ }^{2} \mathrm{H}_{2}\right]$ gibberellin $\mathrm{A}_{20}$-glucoside and $\left[17,17-{ }^{2} \mathrm{H}_{2}\right]$ gibberellin $\mathrm{A}_{20}$-glucosyl ester by Azospirillum lipoferum cultured in a nitrogen-free biotin-Based chemically-defined medium. Plant Growth Regulator, 23, 179-182.

Rodríguez, H., \& Fraga, R. (1999). Phosphate solubilizing bacteria and their role in plant growth promotion. Biotecnology Advances, 17, 319-339.

Servicio de Información y Estadística Agroalimentaria y Pesquera (SIAP). (2012). Sistema de In- formación Agropecuaria de Consulta (SIACÓN) 1980-2003. Secretaría de Agricultura, Ganadería, Desarrollo Rural, Pesca y Alimentación.

Statistical Analysis System (SAS). (1999-2000). SAS/STAT user's Guide: Ver 8.1. Cary NC, USA: SAS Institute Inc.

Steenhoudt, O., \& Vanderleyden, J. (2000). Azospirillum, a free-living nitrogen-fixing bacterium closely associated with grasses: genetic, biochemical and ecological aspects. FEMS Microbiology Reviews, 24, 487-506.

Tortora, M.L., Diaz-Ricci, J.C. \& Pedraza, R.O. (2011). Azospirillum brasilense siderophores with antifungal activity against Colletotrichum acutatum. Archives of Microbiology, 193, 275-286.

Vital, L., \& Mendoza, H.A. (2014). Azospirillum: habitante de las gramíneas. Revista de divulgación Científica y Tecnológica de la Universidad Veracruzana, XXVII(2). 